Article

\title{
New Insights into Sensitization Mechanism of the Doped Ce (IV) into Strontium Titanate
}

\author{
Taiping Xie ${ }^{1,2, *(1)}$, Yuan Wang ${ }^{3,4}$, Chenglun Liu ${ }^{2,4}$ and Longjun $\mathrm{Xu}^{2, *}$ \\ 1 Chongqing Key Laboratory of Extraordinary Bond Engineering and Advanced Materials \\ Technology (EBEAM), Yangtze Normal University, Chongqing 408100, China \\ 2 State Key Laboratory of Coal Mine Disaster Dynamics and Control, Chongqing University, \\ Chongqing 400044, China; xlclj@cqu.edu.cn \\ 3 Environmental Monitoring Center Station of Suining City, Suining 629000, China; wangyuan@163.com \\ 4 College of Chemistry and Chemical Engineering, Chongqing University, Chongqing 400044, China \\ * Correspondence: deartaiping@163.com (T.X.); xulj@cqu.edu.cn (L.X.)
}

Received: 17 March 2018; Accepted: 18 April 2018; Published: 23 April 2018

\begin{abstract}
SrTiO}_{3}$ and $\mathrm{Ce}^{4+}$ doped $\mathrm{SrTiO}_{3}$ were synthesized by a modified sol-gel process. The optimization synthesis parameters were obtained by a series of single factor experiments. Interesting phenomena are observable in $\mathrm{Ce}^{4+}$ doped $\mathrm{SrTiO}_{3}$ systems. $\mathrm{Sr}^{2+}$ in $\mathrm{SrTiO}_{3}$ system was replaced by $\mathrm{Ce}^{4+}$, which reduced the surface segregation of $\mathrm{Ti}^{4+}$, ameliorated agglomeration, increased specific surface area more than four times compared with pure $\mathrm{SrTiO}_{3}$, and enhanced quantum efficiency for $\mathrm{SrTiO}_{3}$. Results showed that $\mathrm{Ce}^{4+}$ doping increased the physical adsorption of $\mathrm{H}_{2} \mathrm{O}$ and adsorbed oxygen on the surface of $\mathrm{SrTiO}_{3}$, which produced additional catalytic active centers. Electrons on the $4 \mathrm{f}$ energy level for $\mathrm{Ce}^{4+}$ produced new energy states in the band gap of $\mathrm{SrTiO}_{3}$, which not only realized the use of visible light but also led to an easier separation between the photogenerated electrons and holes. $\mathrm{Ce}^{4+}$ repeatedly captured photoelectrons to produce $\mathrm{Ce}^{3+}$, which inhibited the recombination between photogenerated electrons and holes as well as prolonged their lifetime; it also enhanced quantum efficiency for $\mathrm{SrTiO}_{3}$. The methylene blue (MB) degradation efficiency reached $98.7 \%$ using $3 \mathrm{~mol} \% \mathrm{Ce}^{4+}$ doped $\mathrm{SrTiO}_{3}$ as a photocatalyst, indicating highly photocatalytic activity.
\end{abstract}

Keywords: strontium titanate; Ce(IV); doping modification; photocatalyst

\section{Introduction}

$\mathrm{SrTiO}_{3}$ is a good stability photocatalyst, possessing a relative narrow band gap. It is a promising function material which has been widely used in water decomposition to produce hydrogen, degradation of organic pollutants, and photochemical cells fields [1].

The excitation wavelength for $\mathrm{SrTiO}_{3}$ is $387 \mathrm{~nm}$, which places it in UV light range. Visible light range is from 400 to $700 \mathrm{~nm}$, occupying $50 \%$ of the solar light spectrum [2]. Therefore, an extension of the absorption light range of $\mathrm{SrTiO}_{3}$ into visible light may promote additional practical applications.

Many researchers have successfully prepared nano-structured $\mathrm{SrTiO}_{3}$ by various synthesis methods. However, these methods have several disadvantages; for example, low yield, high pollution, high cost, and complicated preparation processes. Accordingly, an exploration of environmentally friendly and low cost synthesis approaches for nano-SrTiO 3 is important.

The function of doped ions is to capture and release photogenerated carriers quickly [3], thereby controlling the diffusion of photogenerated carriers in the catalyst particles, increasing the lifetime of photogenerated carriers, and improving the photocatalytic performance of a single-component photocatalyst. 
The unique electronic structure of rare earth elements provides several thermodynamic and kinetic advantages [4]. Such elements have variable valence oxidation states under certain conditions. In the photocatalytic reaction process, variable valence can effectively transfer photogenerated electrons to prolong the time needed for the effective separation between photogenerated electrons and holes. Concurrently, the amount of rare earth elements can change the band gap of a single-component photocatalyst and expand its light absorption range.

The rare earth element cerium (Ce) can produce multiple electronic configurations and absorb visible light. It is the ideal application by which to dope elements for photocatalyst modification. Previous research has suggested [5-9] electron transfer between $\mathrm{Ce}^{4+}$ and $\mathrm{Ce}^{3+}$ may enhance photocatalytic activity of $\mathrm{ZnO}, \mathrm{Al}_{2} \mathrm{O}_{3}$, and $\mathrm{TiO}_{2}$ as a result of the Ce dopant capturing the photogenerated electrons and suppressing the recombination of electron-hole pairs. In addition, an appropriate amount of doped Ce may enhance the property of corrosion resistance to ensure reuse for the modified products. Nevertheless, modification research for $\mathrm{SrTiO}_{3}$ by doping $\mathrm{Ce}^{4+}$ has not yet been reported.

Here, we report an environmentally friendly and low cost synthesis method with a simple preparation process in which $\mathrm{Ce}^{4+}$ doped $\mathrm{SrTiO}_{3}$ in situ synthesis was carried out to modify $\mathrm{SrTiO}_{3}$.

\section{Experimental Procedures}

All reagents were of analytical grade purity and used directly without further purification except that of $\mathrm{SrCO}_{3}$. The water used in all experiment processes was deionized water.

\subsection{Preparation of Pure $\mathrm{SrTiO}_{3}$}

$\mathrm{SrCO}_{3}$ was prepared according to the sol-gel method. A transparent mixed solution (marked A), including $1.47 \mathrm{~g} \mathrm{SrCO}_{3}$ and tartaric acid with different ratios, was prepared by mixing and stirring at $60^{\circ} \mathrm{C}$ for $10 \mathrm{~min}$. Subsequently, $3.4 \mathrm{~mL}$ butyl titanate was added to the (A) solution under stirring conditions at $80^{\circ} \mathrm{C}$ to form a yellow homogeneous sol. The prepared homogeneous sol was dried at $90^{\circ} \mathrm{C}$ for $10 \mathrm{~h}$ to obtain dry gel. The resultant product was obtained by calcining the dry gel at $800{ }^{\circ} \mathrm{C}$ for $2 \mathrm{~h}$.

\subsection{Preparation of $\mathrm{Ce}$-Doped $\mathrm{SrTiO}_{3}$}

Ce-doped $\mathrm{SrTiO}_{3}$ was prepared according to the in situ sol-gel method. Under the optimum conditions of $\mathrm{SrTiO}_{3}$ preparation, ammonium ceric nitrate was added to the (A) solution. The addition amount (x) was $1 \mathrm{~mol} \% \sim 4 \mathrm{~mol} \%$. Other processes were not changed. It could be observed from the resultant product that an increase in the amount of ammonium ceric nitrate doped corresponded to a gradually deepening orange color in the product.

\subsection{Materials Characterizations}

Fourier transform infrared spectroscopy (FTIR) spectra of samples were recorded on an FTIR (Perkin-Elmersystem 2000, Akron, OH, USA) spectrometer using $\mathrm{KBr}$ powder-pressed pellets. Phase identification via X-ray diffraction (XRD) was conducted on an X-ray diffractometer (Shimadzu, XRD-6000, Kyoto, Japan) using $\mathrm{Cu} \mathrm{K} \alpha$ irradiation at a scanning rate of $4^{\circ} \cdot \mathrm{min}^{-1}$ with the $2 \theta$ range of $20^{\circ}-70^{\circ}$. X-ray photoelectron spectroscopy (XPS) measurements were carried out on an XPS-XSAM800 (Kratos, Manchester, UK) spectrometer with an achromatic Al $\mathrm{K}_{\alpha} \mathrm{X}$-ray source and an analytical chamber with a base pressure of $2 \times 10^{-7} \mathrm{~Pa}$. The X-ray gun was operated at $180 \mathrm{~W}(12 \mathrm{kV}, 15 \mathrm{~mA})$. The Brunauer-Emmett-Teller (BET) special surface area was determined through $\mathrm{N}_{2}$ adsorption at $77 \mathrm{~K}$ using an adsorption instrument (ASAP-2020, Micromeritics, Norcross, GA, USA). The samples' morphologies and microstructures were observed via a scanning electron microscopy (SEM, FEI, F50, ZEISS, Oberkochen, Germany) The UV-vis diffuse reflectance spectra (DRS) of samples were measured using a UV-vis spectrophotometer (TU1901, Beijing Purkinje, Beijing, China). $\mathrm{BaSO}_{4}$ was used as a reflectance standard. 


\subsection{Photocatalytic Activity Tests}

$100 \mathrm{~mL}$ of methylene blue (MB) aqueous solution with a given concentration and its corresponding photocatalyst dosage of $1 \mathrm{~g} / \mathrm{L}$ were added into a quartz container and stirred for $1 \mathrm{~h}$ in the dark to reach the adsorption-desorption equilibrium. A $500 \mathrm{~W}$ Xe lamp equipped with $\mathrm{UV}$ cut-off filter was used as the visible light source $(\lambda \geq 420 \mathrm{~nm})$. At the given irradiation time intervals, a series of the reaction solution was sampled and the absorption was measured with the UV-vis spectrophotometer (TU1901, Beijing Purkinje, Beijing, China).

\subsubsection{Effect of Initial Concentration of Methylene Blue on Photocatalytic Activity}

According to the literature, initial concentration had a significant influence on the photocatalytic activity. A greater concentration of methylene blue produced a deeper color, which significantly affected the absorption of light irradiation for photocatalysts. Too low of a methylene blue concentration cannot fully reflect the photocatalytic activity. Therefore, to completely reveal photocatalytic activity of $\mathrm{SrTiO}_{3}$, a better initial concentration should be chosen via single factor experiment.

Here, we prepared a series of MB solutions with different concentrations $(20 \mathrm{mg} / \mathrm{L}, 50 \mathrm{mg} / \mathrm{L}$, $100 \mathrm{mg} / \mathrm{L}, 150 \mathrm{mg} / \mathrm{L}$, and $200 \mathrm{mg} / \mathrm{L}$ ). The degradation rate after $2 \mathrm{~h}$ reaction was tested using pure $\mathrm{SrTiO}_{3}$ and Ce-doped $\mathrm{SrTiO}_{3}$ as photocatalyst.

\subsubsection{Effect of Ce Doping Amount on Photocatalytic Activity}

In order to investigate the effect of the Ce doping amount on the photocatalytic activity of $\mathrm{SrTiO}_{3}$, the photocatalysis mechanism was discussed and comparative experiments were performed. Four varieties of $\mathrm{SrTiO}_{3}$ with Ce content of $1 \mathrm{~mol} \%-4 \mathrm{~mol} \%$ were measured using photocatalytic reaction.

\section{Results and Discussion}

\subsection{Optimization of Synthesis Conditions}

\subsubsection{Effect of Tartaric Acid Dosage}

In this synthesis process, tartaric acid was used as the solvent of $\mathrm{SrCO}_{3}$ and also as the complexing agent of tetrabutyl titanate. The following reaction occurred as a solvent for $\mathrm{SrCO}_{3}$ :

$$
\mathrm{CO}_{3}{ }^{2-}+\mathrm{HOOCCHOHCHOHCOOH} \rightarrow \mathrm{CO}_{2} \uparrow+\mathrm{H}_{2} \mathrm{O}+{ }^{-} \mathrm{OOCCHOHCHOHCOO}
$$

The formation of homogeneous sol-gel via the complexation reaction between butyl titanate and tartaric acid was divided into two steps:

First, the stable organic complex of $\mathrm{Ti}^{4+}$ was formed by mixing butyl titanate with tartaric acid under stirring condition.

$$
\begin{aligned}
& \mathrm{Ti}\left(\mathrm{OC}_{4} \mathrm{H}_{9}\right)_{4}+\mathrm{xHOOCCHOHCHOHCOOH} \rightarrow \mathrm{Ti}\left(\mathrm{OC}_{4} \mathrm{H}_{9}\right)_{4-2 \mathrm{x}}+\mathrm{xHOCH}_{2} \mathrm{CHOHCHOHCH} \mathrm{H}_{2} \mathrm{OH} \\
& \mathrm{Ti}\left(\mathrm{OC}_{4} \mathrm{H}_{9}\right)_{4}+\mathrm{yHOOCCHOHCHOHCOOH}+\mathrm{xH}_{2} \mathrm{O} \rightarrow \mathrm{Ti}(\mathrm{OH})_{x}(\mathrm{OOCCHOHCHOHCOO})_{y}+4 \mathrm{HOC}_{4} \mathrm{H}_{9}
\end{aligned}
$$

Second, $\mathrm{Ti}^{4+}$ complexes could create a network structure in the sol-gel system by cross-linking action. In this process, $\mathrm{Sr}^{2+}$ ions were uniformly distributed in the sol-gel system by electrostatic action.

It can be seen from the reaction process that the amount of tartaric acid could not only dissolve $\mathrm{SrCO}_{3}$ but also ensure the complete complexation of $\mathrm{Ti}^{4+}$ with tartaric acid in order to obtain a stable organic complex including $\mathrm{Ti}^{4+}$. 
When the amount of organic complexing agent was too small, the reaction system produced precipitation phenomenon; this resulted from the minimal presence of the complexing agent, which did not fully react with the metal ion. Accordingly, metal salt precipitation and crystallization made the formation of a clear and transparent sol more difficult.

In addition, tartaric acid also acts as a stabilizing agent in the formation of network-structured sol-gels through the cross-linking reaction between tartaric acid and $\mathrm{Ti}^{4+}$. In the sol-gel method process, the entire reaction system has no active group for polycondensation reaction.

The reaction between $\mathrm{Ti}^{4+}$ complex molecules was achieved only through the formation of hydrogen bonds from water molecules instead of polycondensation reaction. However, the hydrogen bond was not stable and easily disconnected. Accordingly, this kind of gel with cross-linking of hydrogen bonds easily absorbed water and subsequently was moisturized in the atmosphere. When the deliquescence gel was sintered at a high temperature, an undesired agglomeration phenomenon was observed in the resultant product. Fortunately, the tartaric acid contained numerous hydroxyl groups which could replace the hydrogen bonds via the crosslinking reaction process. Thus, a more stable, uniform transparent gel was formed.

Therefore, in the preparation process, the amount of tartaric acid must meet the needs of the solvent for $\mathrm{SrCO}_{3}$, the complexing agent of butyl titanate, and the stabilizer of the entire reaction system. However, an excessive amount of complexing agent in the preparation process might incur high costs.

To adjust the mole ratio of $\mathrm{Sr}^{2+}$ and tartaric acid to 2:1-1:5 in the preparation process of $\mathrm{SrTiO}_{3}$, the optimal dosage of tartaric acid was chosen by observing sol transparency and powder agglomeration after sintering, calculating relative crystallinity (The relative crystallinity can be obtained by processing XRD data of the sample.), and photocatalytic activity of the products. Table 1 lists the experimental phenomena and relative crystallinity of $\mathrm{SrTiO}_{3}$ in the system with different molar ratios of $\mathrm{Sr}^{2+}$ and tartaric acid (2:1-1:5).

Table 1. Experimental phenomena and relative crystallinity of $\mathrm{SrTiO}_{3}$ in the system with different molar ratios of $\mathrm{Sr}^{2+}$ and tartaric acid.

\begin{tabular}{cccc}
\hline Sample Number & $\mathbf{n}_{\left(\mathbf{S r}^{2+}\right)} / \mathbf{n}_{(\text {tartaric acid) }}$ & Sol State & Relative Crystallinity (\%) \\
\hline 1 & $2: 1$ & white precipitation & 23 \\
2 & $1: 1$ & white precipitation & 27 \\
3 & $1: 2$ & transparent & 78 \\
4 & $1: 3$ & transparent & 85 \\
5 & $1: 4$ & transparent & 89 \\
6 & $1: 5$ & transparent & 89 \\
\hline
\end{tabular}

As seen in Table 1, the molar ratio of $\mathrm{Sr}^{2+}$ and tartaric acid was higher than 1:1, the white precipitation was observed, and the relative crystallinity of the product was low. These phenomena indicated that tartaric acid added in the system was not sufficient to completely generate complexation reaction with $\mathrm{Ti}^{4+}$.

To further investigate the influence of tartaric acid dosage on the photocatalytic activity of $\mathrm{SrTiO}_{3}$, the samples were used in a photocatalytic activity test, and the experimental results are shown in Figure 1. It can be seen that the photocatalytic activity of $\mathrm{SrTiO}_{3}$ for methylene blue was greatly affected by the amount of tartaric acid. When the molar ratio of $\mathrm{Sr}^{2+}$ and tartaric acid was less than $1: 4$, the photocatalytic activity was highest. In contrast, when the molar ratio of $\mathrm{Sr}^{2+}$ and tartaric acid was 1:5, the photocatalytic activity was lower. Therefore, the optimum molar ratio of $\mathrm{Sr}^{2+}$ and tartaric acid was 1:4.

Concurrently, Table 1 and Figure 1 also demonstrate that the degradation rate of methylene blue was enhanced with the increase in the relative crystallinity of the as-prepared $\mathrm{SrTiO}_{3}$. This provided a theoretical basis for the modification of $\mathrm{SrTiO}_{3}$. 


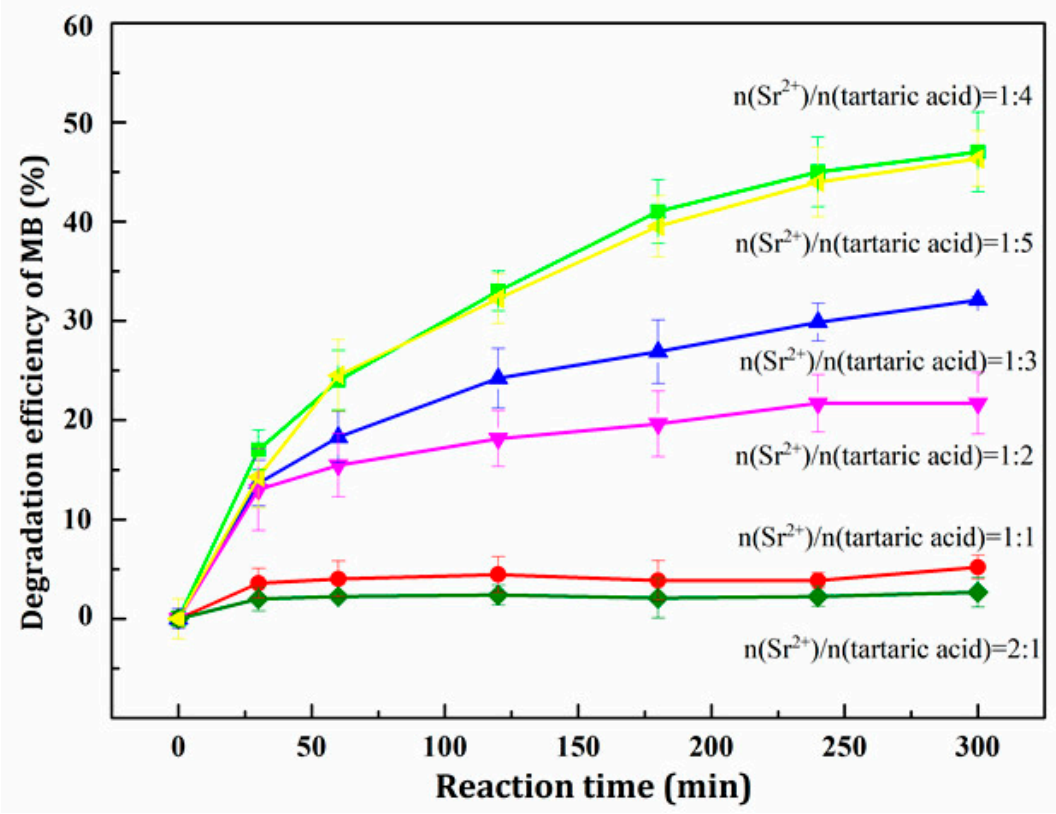

Figure 1. Effect of different dosage of tartaric acid on degradation efficiency of MB.

\subsubsection{Effect of Distilled Water Amount}

The dissolution of $\mathrm{SrCO}_{3}$ and tartaric acid, the multistage ionization of tartaric acid, and the formation of sol-gel by the strontium titanate precursor all occurred in aqueous solution. Therefore, the amount of distilled water affected the preparation process of $\mathrm{SrTiO}_{3}$. When the water content in the solution was insufficient, the solution generated precipitation phenomenon due to low dissolution ability to $\mathrm{SrCO}_{3}$ and tartaric acid. Meanwhile, tartaric acid belonged to $\mathrm{H}_{2} \mathrm{~A}$-type acid. Accordingly, there was secondary ionization equilibrium in the solution.

$$
\begin{array}{ll}
\mathrm{HOOCCHOHCHOHCOOH} \leftrightarrow{ }^{-} \mathrm{OOCCHOHCHOHCOOH}+\mathrm{H}^{+} & \mathrm{pKa}_{1}=2.95 \\
{ }^{-} \mathrm{OOCCHOHCHOHCOOH} \leftrightarrow{ }^{-}{ }^{-} \mathrm{OOCCHOHCHOHCOO}{ }^{-}+\mathrm{H}^{+} & \mathrm{pKa}_{2}=3.97
\end{array}
$$

Obviously, the amount of distilled water affected the $\mathrm{pH}$ value of the solution. The ionization degree of tartaric acid was different in solutions with various $\mathrm{pH}$ values. On the one hand, the insufficient amount of distilled water restrained the secondary ionization of tartaric acid, which led to difficulty in obtaining clear sol. On the other hand, although additional distilled water helped to dissolve $\mathrm{SrCO}_{3}$ and tartaric acid, too much water reduced the collision probability of $\mathrm{Ti}^{4+}$ and tartrate ions in solution, which brought about the incomplete complexation reaction.

At the same time, excessive water extended the drying time and increased the cost. Only when the water content was appropriate did the following reactions occur: (a) the $\mathrm{SrCO}_{3}$ and tartaric acid fully dissolved, (b) the tartaric acid was completely ionized, and (c) complexation reaction occurred completely. Only when such conditions were met could a clear and transparent homogeneous sol be obtained.

To determine the optimum amount of distilled water $(5-25 \mathrm{~mL})$ factors such as the observation of sol transparency, powder agglomeration after sintering, calculation of relative crystallinity, and photocatalytic activity of products were considered.

Table 2 provides the experimental phenomena for $\mathrm{SrTiO}_{3}$ and the relative crystallinity determined by adjusting the amount of distilled water. It can be seen from Table 2 that when the amount of distilled water was less than $10 \mathrm{~mL}$, the solubility of $\mathrm{SrCO}_{3}$ and tartaric acid was relatively weak, the secondary ionization of tartaric acid was inhibited, and the white precipitate in the sol system could be observed. When the amount of distilled water was $15 \mathrm{~mL}$, the relative crystallinity of the product was still not 
high despite a transparent sol. When the amount of distilled water was $25 \mathrm{~mL}$, a white precipitate appeared in the sol system, indicating that the distilled water was excessive, that the reaction in the system was incomplete, and that the drying time would be lengthened.

Table 2. Experimental phenomena and relative crystallization of $\mathrm{SrTiO}_{3}$ prepared with different amounts of water.

\begin{tabular}{ccccc}
\hline Sample Number & $\mathbf{H}_{\mathbf{2}} \mathbf{O}(\mathbf{m L})$ & Sol State & Drying Time (h) & Relative Crystallinity (\%) \\
\hline 1 & 5 & white precipitation & 5 & 13 \\
2 & 10 & white precipitation & 6 & 20 \\
3 & 15 & transparent & 8 & 80 \\
4 & 20 & transparent & 10 & 89 \\
5 & 25 & white precipitation & 15 & 89 \\
\hline
\end{tabular}

To investigate the influence of the amount of distilled water on the photocatalytic activity of the as-prepared $\mathrm{SrTiO}_{3}$, the samples were used for the photocatalytic activity test. Results are shown in Figure 2. It can be seen that when the amount of distilled water was $20 \mathrm{~mL}$, methylene blue had the highest degradation rate. Therefore, the optimum amount of distilled water was found to be $20 \mathrm{~mL}$.

In addition, Table 2 and Figure 2 demonstrate that the higher the crystallinity of the catalyst, the higher the rate of $\mathrm{MB}$ degradation.

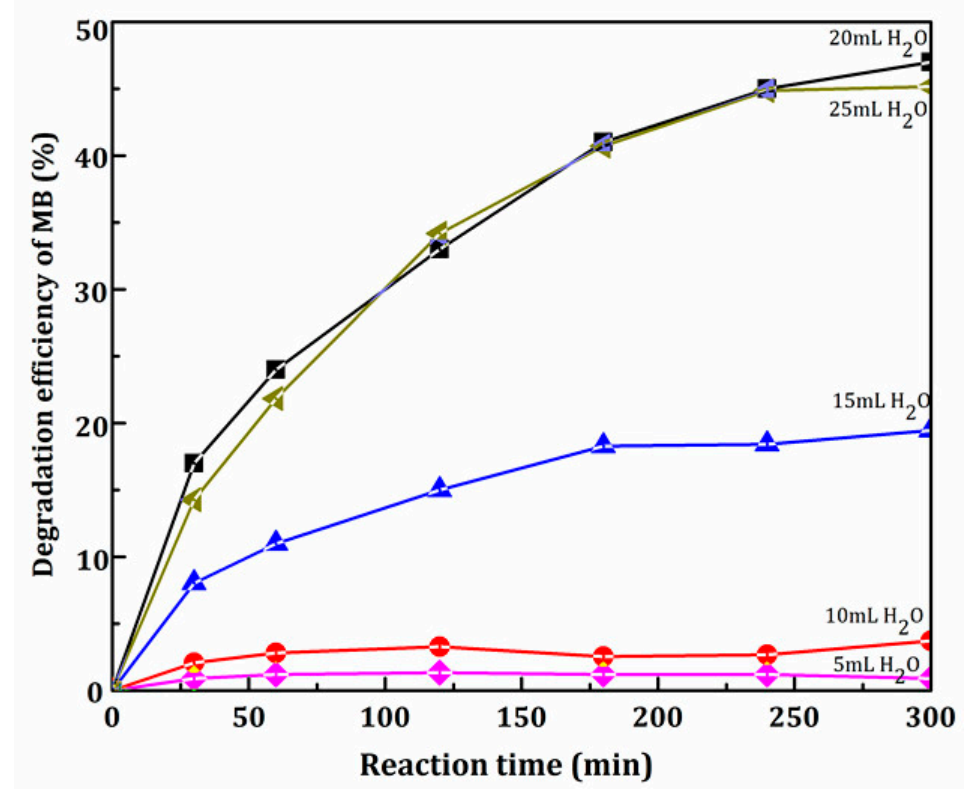

Figure 2. Effect of different dosage of water on MB degradation.

\subsection{XRD, IR, and SEM Analysis of $\mathrm{SrTiO}_{3}$}

In the preparation process of $\mathrm{SrTiO}_{3}$, the molar ratio of $\mathrm{Sr}^{2+}$ to tartaric acid was less than 1:4 and the amount of distilled water was $20 \mathrm{~mL}$. The as-prepared $\mathrm{SrTiO}_{3}$ was characterized by XRD, IR, BET, and SEM. Figure 3 shows the XRD pattern of $\mathrm{SrTiO}_{3}$ prepared under optimum conditions. Compared with the standard card, diffraction peaks at $2 \theta=23.0^{\circ}, 32.4^{\circ}, 40.4^{\circ}, 57.8^{\circ}, 67.8^{\circ}, 77.2^{\circ}$, and $79.9^{\circ}$ belonged to the $100,110,111,200,211,220$, and 310 of the crystal phase of $\mathrm{SrTiO}_{3}$ [10-12], respectively. It can be seen that the prepared $\mathrm{SrTiO}_{3}$ had a good crystal form and a high diffraction peak intensity. The average particle size of $\mathrm{SrTiO}_{3}$ was $20.8 \mathrm{~nm}$ calculated by the Debye-Scherrer formula, which reached nanometer level. The crystallinity of $\mathrm{SrTiO}_{3}$ was $89 \%$. The BET test results indicated that the specific surface area was $11.8 \mathrm{~m}^{2} / \mathrm{g}$. The specific surface area was relatively small, 
which was not conducive to improving photocatalytic activity. Therefore, subsequent experiments to modify $\mathrm{SrTiO}_{3}$ to improve its crystallinity and to increase its specific surface area were conducted.

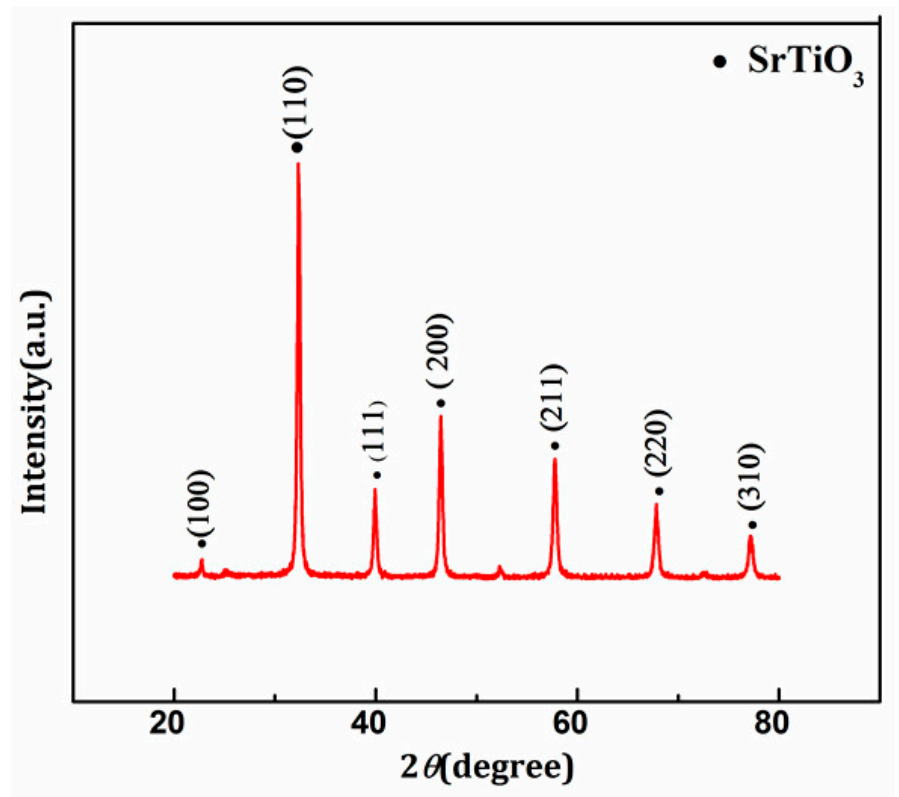

Figure 3. XRD pattern of pure $\mathrm{SrTiO}_{3}$

Figure 4 displays the FTIR spectrum of $\mathrm{SrTiO}_{3}$. The absorption peaks at $3420 \mathrm{~cm}^{-1}$ and $1629 \mathrm{~cm}^{-1}$ originated from hydroxyl vibration [3]. It is speculated that the hydroxyl group was derived from the adsorption water on the surface of the sample. The absorption peak at $557 \mathrm{~cm}^{-1}$ belonged to the characteristic stretching vibration of the Sr-Ti-O bond [11], which confirmed $\mathrm{SrTiO}_{3}$ was prepared successfully.

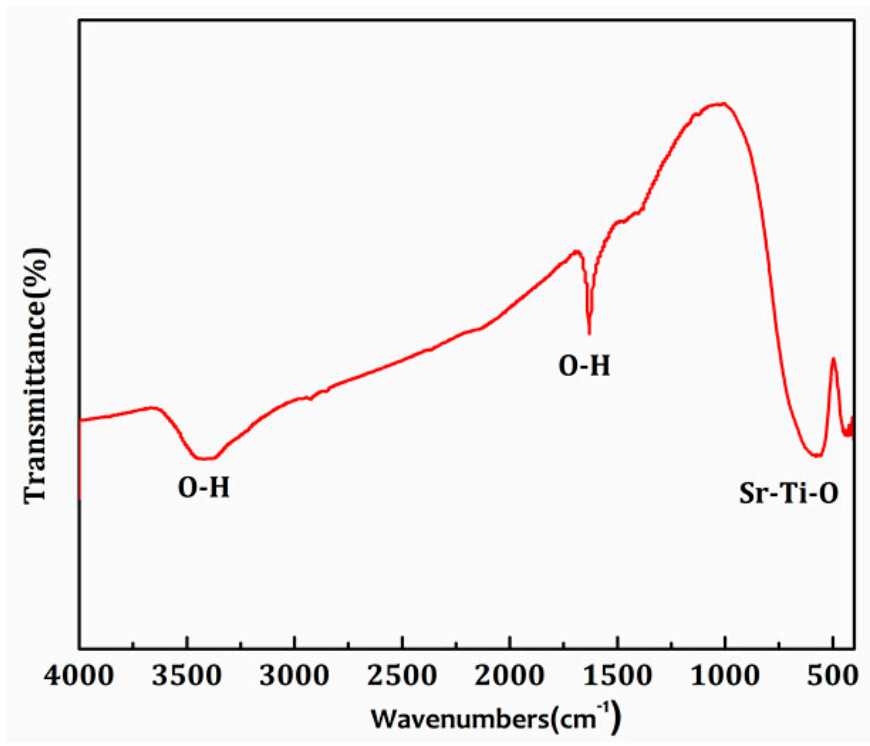

Figure 4. FTIR spectra of pure $\mathrm{SrTiO}_{3}$.

It can be seen from Figure 5 that pure $\mathrm{SrTiO}_{3}$ particles were spherical. Agglomeration was formed in part as a result of the volatilization or decomposition of organic compounds during the roasting process. 


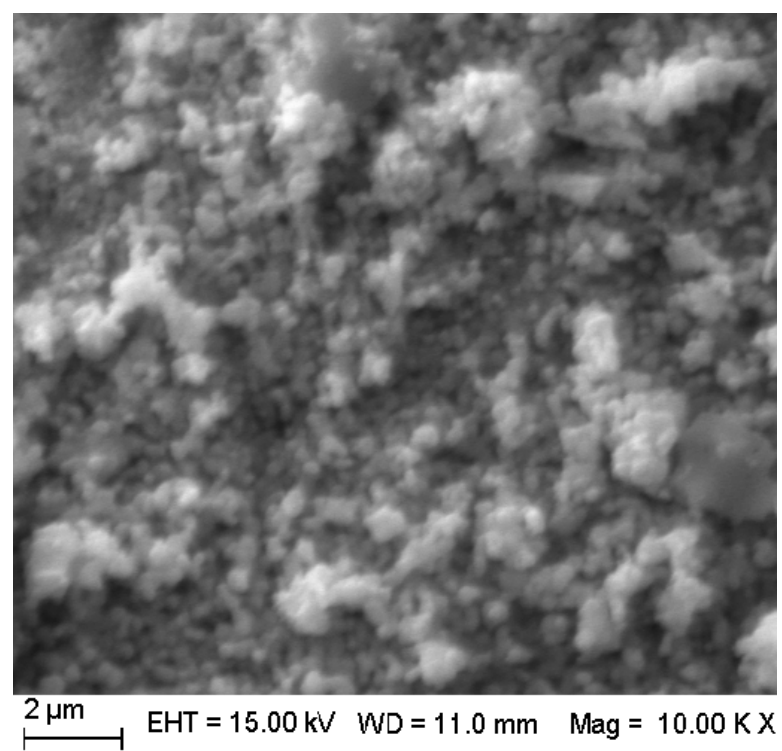

Figure 5. SEM images of pure $\mathrm{SrTiO}_{3}$.

\subsection{XRD, BET, IR, XPS, and SEM Analysis of Ce $e^{4+}$ Doped $\mathrm{SrTiO}_{3}$}

From Figure 6a, the diffraction peaks of $\mathrm{SrTiO}_{3}$ appear in each of the patterns. The XRD diffraction peaks of $\mathrm{Ce}^{4+}$ doped $\mathrm{SrTiO}_{3}$ from $1 \mathrm{~mol} \%$ to $4 \mathrm{~mol} \%$ were in good agreement with that of pure $\mathrm{SrTiO}_{3}$, indicating that the incorporation of $\mathrm{Ce}^{4+}$ could not change the crystal structure of $\mathrm{SrTiO}_{3}$. There was no $\mathrm{Ce}^{4+}$ independent characteristic diffraction peak in the spectra, demonstrating that $\mathrm{Ce}^{4+}$ was highly dispersed into $\mathrm{SrTiO}_{3}$, even into the crystal lattice of $\mathrm{SrTiO}_{3}$. Figure $6 \mathrm{~b}$ demonstrates that, with the increase of the doping amount of $\mathrm{Ce}^{4+}$, the diffraction peak of crystal plane of $\mathrm{SrTiO}_{3}$ (110) gradually broadened and shifted to a higher $2 \theta$ direction, further indicating that $\mathrm{Ce}^{4+}$ entered the framework of $\mathrm{SrTiO}_{3}$ [5-7] and substituted $\mathrm{Sr}^{2+}$ in $\mathrm{SrTiO}_{3}$ system. The ionic radius for $\mathrm{Ti}^{4+}, \mathrm{Ce}^{4+}$, and $\mathrm{Sr}^{2+}$ showed a higher order of increase from 68 to $113 \mathrm{pm}$, namely, $\mathrm{r}_{\mathrm{Ti}^{4+}}(68 \mathrm{pm})<\mathrm{r}_{\mathrm{Ce}^{4+}}(92 \mathrm{pm})<\mathrm{r}_{\mathrm{Sr}^{2+}}(113 \mathrm{pm})$. A replacement of $\mathrm{Ce}^{4+}$ for $\mathrm{Sr}^{2+}$ would reduce the lattice parameter (d) according to the Bragg law $(\mathrm{n} \lambda=2 \mathrm{~d} \sin \theta, \mathrm{n}=1)$. The decrease in $\mathrm{d}$ values would cause the shift of diffraction peaks to high $2 \theta$ direction. The broadening of the manifest diffraction peak indicated that the doped $\mathrm{Ce}^{4+}$ ions inhibited grain growth of $\mathrm{SrTiO}_{3}$.
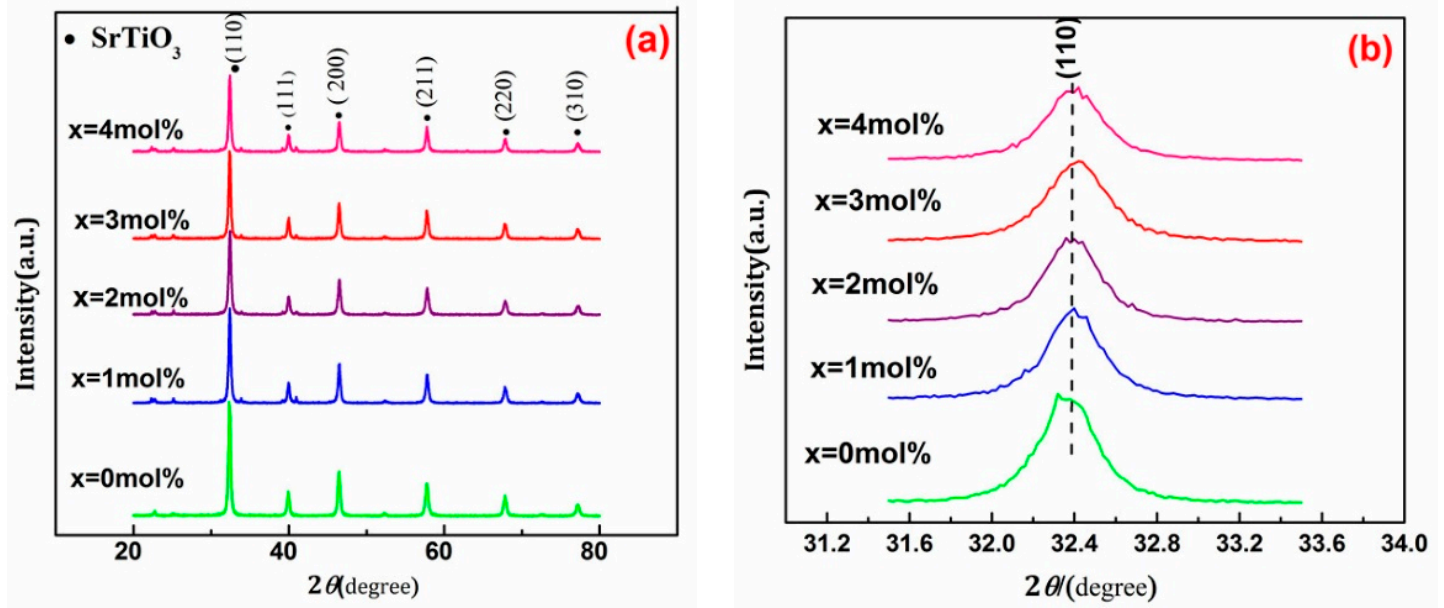

Figure 6. XRD pattern of pure and $1 \mathrm{~mol} \%, 2 \mathrm{~mol} \%, 3 \mathrm{~mol} \%, 4 \mathrm{~mol} \% \mathrm{Ce}^{4+}$ doped $\mathrm{SrTiO}_{3}$. (a) The whole XRD pattern; (b) The local enlargement of the diffraction peaks at $2 \theta=32.4^{\circ}$. 
The average particle size of samples was calculated by the Debye-Scherrer formula. The average particle size of $\mathrm{SrTiO}_{3}$ samples with the doping amount of $\mathrm{Ce}^{4+} 0 \sim 4 \mathrm{~mol} \%$ were $20.8 \mathrm{~nm}, 17.2 \mathrm{~nm}$, $13.3 \mathrm{~nm}, 8.7 \mathrm{~nm}$, and $18.7 \mathrm{~nm}$, respectively. Additionally, compared with pure $\mathrm{SrTiO}_{3}$, the specific surface area and pore volume of $\mathrm{Ce}^{4+}$ doped $\mathrm{SrTiO}_{3}$ samples manifestly increased (See Table 3). The'specific surface area of $3 \mathrm{~mol} \% \mathrm{Ce}^{4+}$ doped $\mathrm{SrTiO}_{3}$ was more than four times higher than that of pure $\mathrm{SrTiO}_{3}$.

Table 3. Specific surface area, pore volume, and average pore diameter of the samples.

\begin{tabular}{|c|c|c|c|}
\hline Catalysts & Surface Area $/\left(\mathrm{m}^{2} \cdot \mathrm{g}^{-1}\right)$ & Pore Volume $/\left(\mathrm{cm}^{3} \cdot \mathrm{g}^{-1}\right)$ & Mean Pore Size/nm \\
\hline $\mathrm{SrTiO}_{3}$ & 11.8 & 0.040 & 13.6 \\
\hline $1 \mathrm{~mol} \% \mathrm{Ce}^{4+}$ doped $\mathrm{SrTiO}_{3}$ & 13.5 & 0.047 & 14.2 \\
\hline $2 \mathrm{~mol} \% \mathrm{Ce}^{4+}$ doped $\mathrm{SrTiO}_{3}$ & 25.9 & 0.052 & 8.1 \\
\hline $3 \mathrm{~mol} \% \mathrm{Ce}^{4+}$ doped $\mathrm{SrTiO}_{3}$ & 48.7 & 0.132 & 7.7 \\
\hline $4 \mathrm{~mol} \% \mathrm{Ce}^{4+}$ doped $\mathrm{SrTiO}_{3}$ & 12.7 & 0.048 & 15.2 \\
\hline
\end{tabular}

$\mathrm{Sr}^{2+}$ radius was relatively large, leading to relatively large lattice parameters for a $\mathrm{SrTiO}_{3}$ crystal system. $\mathrm{Ti}^{4+}$ in the oxygen octahedron system had a good mobility and an inferior stability, which facilitated the fracture of $\mathrm{Ti}-\mathrm{O}$ bonds. Concurrently, $\mathrm{Ti}^{4+}$ produced a positive charge at the grain boundary. The replacement of $\mathrm{Sr}^{2+}$ by $\mathrm{Ce}^{4+}$ with a smaller radius engendered volume contraction of the unit cell. Thus, the activity scope of $\mathrm{Ti}^{4+}$ ion was smaller, and additional $\mathrm{Ti}-\mathrm{O}$ bonds were not easily broken $[13,14]$, leading to a reduction in the positive charge of the grain boundary. Space contraction was generated, leading to the decrease in grain size and further increasing the specific surface area. However, the grain size of $\mathrm{SrTiO}_{3}$ did not continue to decrease with the increase in the content of $\mathrm{Ce}^{4+}$. Compared with $3 \mathrm{~mol} \% \mathrm{Ce}^{4+}$ doped $\mathrm{SrTiO}_{3}$, the average particle size of $4 \mathrm{~mol} \% \mathrm{Ce}^{4+}$ doped $\mathrm{SrTiO}_{3}$ slightly increased. When an excess of $\mathrm{Ce}^{4+}$ gathered on the surface of $\mathrm{SrTiO}_{3}$, a positive charge on the boundary surface increased and space area expanded. Thus, while the crystal grain increased the specific surface area decreased.

Figure 7 displays the FTIR curves of the samples. FTIR curves of the differing amounts of $\mathrm{Ce}^{4+}$ doped $\mathrm{SrTiO}_{3}$ all exhibited the characteristic absorption peak of hydroxyl vibration at $3420 \mathrm{~cm}^{-1}$ and $1629 \mathrm{~cm}^{-1}$ [15]. It is suggested that the hydroxyl group stemmed from the adsorbed water on the surface of the samples. The absorption peaks at $557 \mathrm{~cm}^{-1}$ were attributed to the stretching vibration of the $\mathrm{Sr}-\mathrm{Ti}-\mathrm{O}$ bond [14]. No additional peaks appeared at this wavelength range for $\mathrm{Ce}^{4+}$ doped $\mathrm{SrTiO}_{3}$. The characteristic absorption peak at $1145 \mathrm{~cm}^{-1}$ for $\mathrm{CeO}_{2}$ was not observed, evincing that doped $\mathrm{Ce}^{4+}$ entered into the crystal lattice of $\mathrm{SrTiO}_{3}$. According to the XRD test results, the Ti-O bond length shortened after the substitution of $\mathrm{Ce}^{4+}$ for $\mathrm{Sr}^{2+}$, and the absorption peak of Ti-O bond widened due to the presence of several with a Sr-Ti-O absorption peak.

Figure 8 shows the XPS spectra. Figure 8 a reveals that the $\mathrm{Ce}^{4+}$ was not detected in the $3 \mathrm{~mol} \%$ $\mathrm{Ce}^{4+}$ doped $\mathrm{SrTiO}_{3}$, indicating that the $\mathrm{Ce}^{4+}$ was indeed highly dispersed in the bulk phase of $\mathrm{SrTiO}_{3}$, which is in accordance with the above analysis. Through quantitative analysis (Table 4), $\mathrm{n}(\mathrm{Sr}) / \mathrm{n}$ (Ti) in pristine $\mathrm{SrTiO}_{3}$ system was 0.96 , possibly signifying the excess $\mathrm{Ti}^{4+}$ distributed on the crystal surface. The content of $\mathrm{Ti}^{4+}$ decreased from $13.77 \%$ to $13.01 \%$ after $3 \mathrm{~mol} \% \mathrm{Ce}^{4+}$ doping, also indicating that the reduction of the content of the crystal surface of $\mathrm{Ti}^{4+}$ was attributable to the substitution of $\mathrm{Ce}^{4+}$ for $\mathrm{Sr}^{2+}$. Simultaneously, the $\mathrm{O}$ content on the surface of $\mathrm{SrTiO}_{3}$ increased. The $\mathrm{O}_{1 \mathrm{~S}}$ peak was fitted. The $\mathrm{SrTiO}_{3}$ of pure $\mathrm{O}_{1 \mathrm{~S}}$ can be divided into three peaks at 529.28, 530.73, and $532.55 \mathrm{eV}[8,16,17]$, respectively, as shown in Figure $8 \mathrm{~b}$ marked " 1 ", " 2 " and " 3 ". The " 1 " peak belonged to the characteristic peak of lattice oxygen, and the " 2 " peak was born of the adsorbed oxygen on the surface. " 3 " corresponded to the characteristic peak of the physisorption water on the sample surface.

After doping, three peaks for $\mathrm{O}_{1 \mathrm{~S}}$ shifted $0.01 \mathrm{eV}, 0.35 \mathrm{eV}$, and $0.31 \mathrm{eV}$ to higher binding energy sites. The smaller atomic radius, the larger both the electronegativity and electron binding energy is. The Ce electronegativity of 1.12 was more than that of $\mathrm{Sr}(0.95)$. After the $\mathrm{Ce}^{4+}$ replaced $\mathrm{Sr}^{2+}$, 
the electron density around Sr and Ti decreased, the shielding effect was weakened, and the electron binding energy increased.

A comparison of Figure $8 \mathrm{~b}$ and $8 \mathrm{c}$ demonstrates that the intensity of " 2 " and " 3 " peaks increased after doping. The surface oxygen adsorption increased from $26.55 \%$ to $28.74 \%$ by calculating the area of three peaks. The physical adsorption of $\mathrm{H}_{2} \mathrm{O}_{1 \mathrm{~S}}$ increased from $17.74 \%$ to $20.8 \%$, which was attributed to an increased specific surface area of doped $\mathrm{Ce}^{4+}$ as well as enhanced adsorption capacity.

Some adsorbed oxygen were able to capture some free electrons on the surface of $\mathrm{SrTiO}_{3}$ to form the active center in the catalytic reaction process. The higher the adsorbed oxygen content on the surface of $\mathrm{SrTiO}_{3}$, the higher the catalytic activity was.

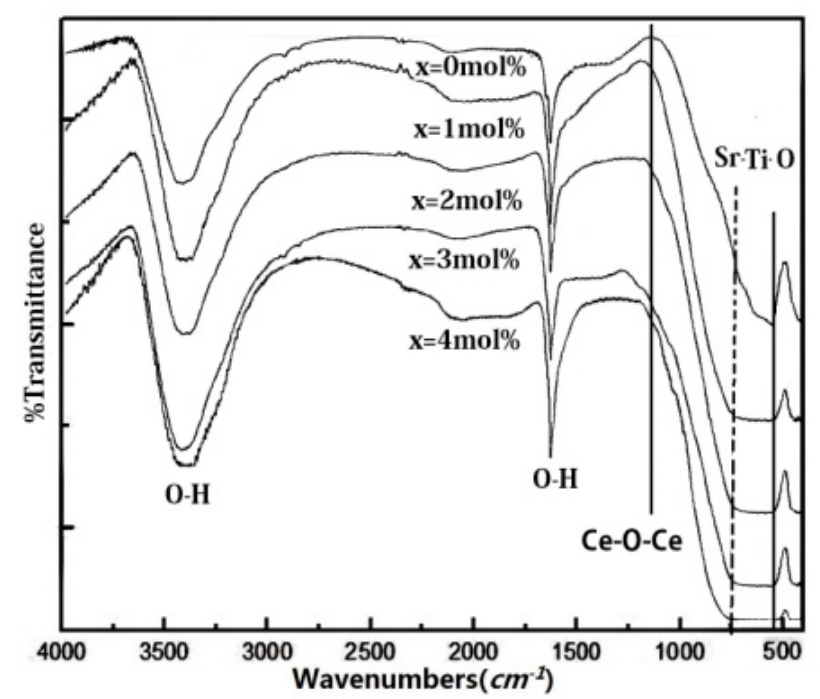

Figure 7. FTIR spectra of pure $\mathrm{SrTiO}_{3}$ and $1 \mathrm{~mol} \%, 2 \mathrm{~mol} \%, 3 \mathrm{~mol} \%, 4 \mathrm{~mol} \% \mathrm{Ce}^{4+}$ doped $\mathrm{SrTiO}_{3}$.

Table 4. Surface atomic composition and atomic ratio of catalysts.

\begin{tabular}{ccccc}
\hline \multirow{2}{*}{ Catalysts } & \multicolumn{2}{c}{ Surface Atomic Composition } & \multicolumn{2}{c}{ Surface Atomic Ratio } \\
\cline { 2 - 5 } & $\mathrm{Sr}$ & $\mathrm{Ti}$ & $\mathbf{O}$ & $\mathbf{n}(\mathbf{S r}) / \mathbf{n}(\mathbf{T i})$ \\
\hline $\mathrm{SrTiO}_{3}$ & $24.18 \%$ & $13.77 \%$ & $55.44 \%$ & 0.96 \\
$3 \mathrm{~mol} \% \mathrm{Ce}^{4+}$ doped $\mathrm{SrTiO}_{3}$ & $25.02 \%$ & $13.01 \%$ & $57.19 \%$ & 1.05 \\
\hline
\end{tabular}

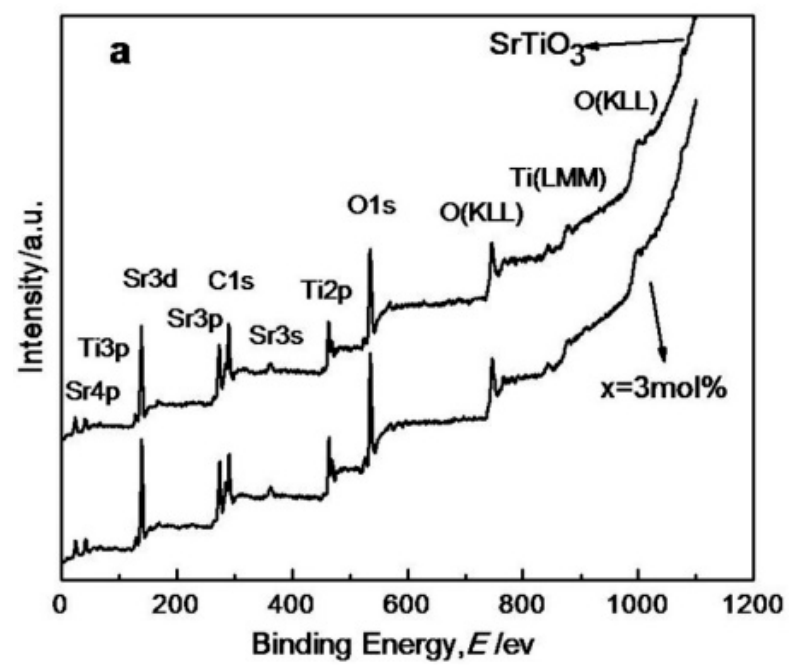

Figure 8. Cont. 

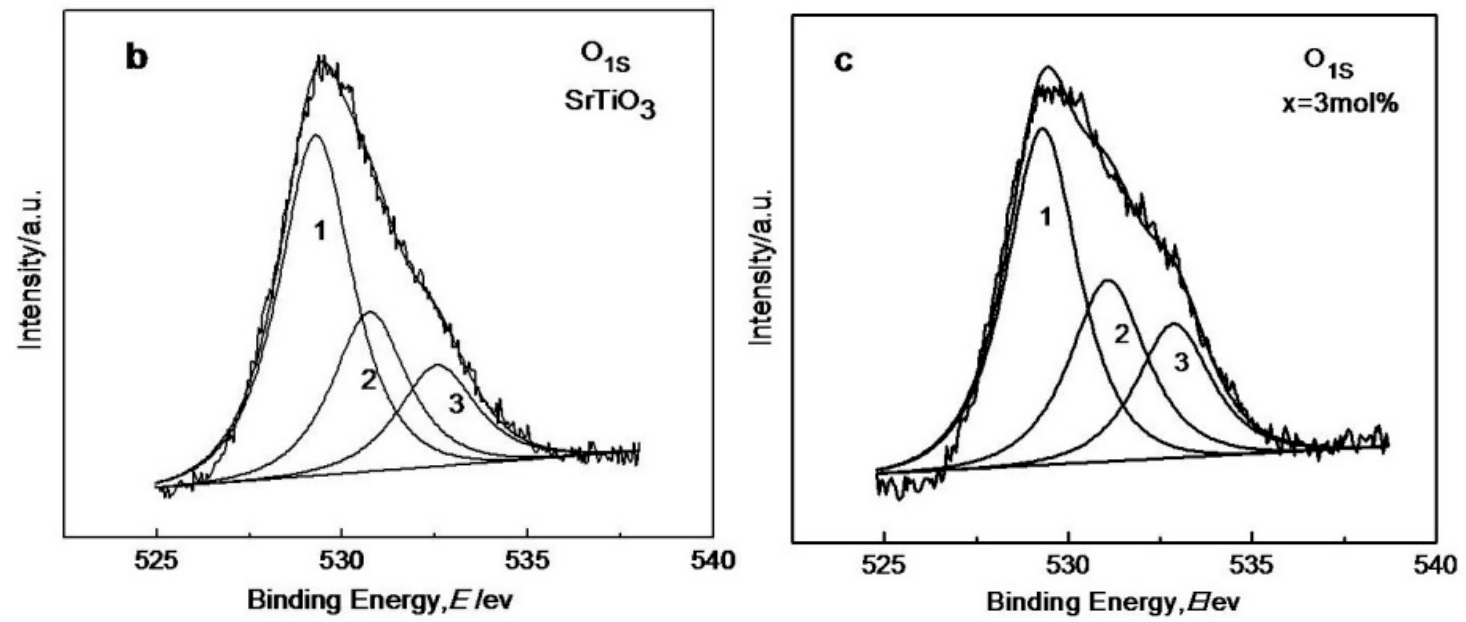

Figure 8. XPS scans for pure and $3 \mathrm{~mol} \% \mathrm{Ce}^{4+}$ doped $\mathrm{SrTiO}_{3}$ (a) Full scan; (b) $\mathrm{O}_{1 \text { s }}$ peaks on pure $\mathrm{SrTiO}_{3} ;$ (c) $\mathrm{O}_{1 \mathrm{~s}}$ peaks on $3 \mathrm{~mol} \% \mathrm{Ce}^{4+}$ doped $\mathrm{SrTiO}_{3}$.

Analysis of the SEM image (See Figure 9) were consistent with those of XRD and BET. It can be seen from Figure 5 that pure $\mathrm{SrTiO}_{3}$ particles were spherical. The observed partial agglomeration was due to the volatilization or decomposition of organic material during the roasting process. However, $3 \mathrm{~mol} \% \mathrm{Ce}^{4+}$ doped $\mathrm{SrTiO}_{3}$ particles were smaller and had uniform distribution. The agglomeration significantly could be ameliorated.

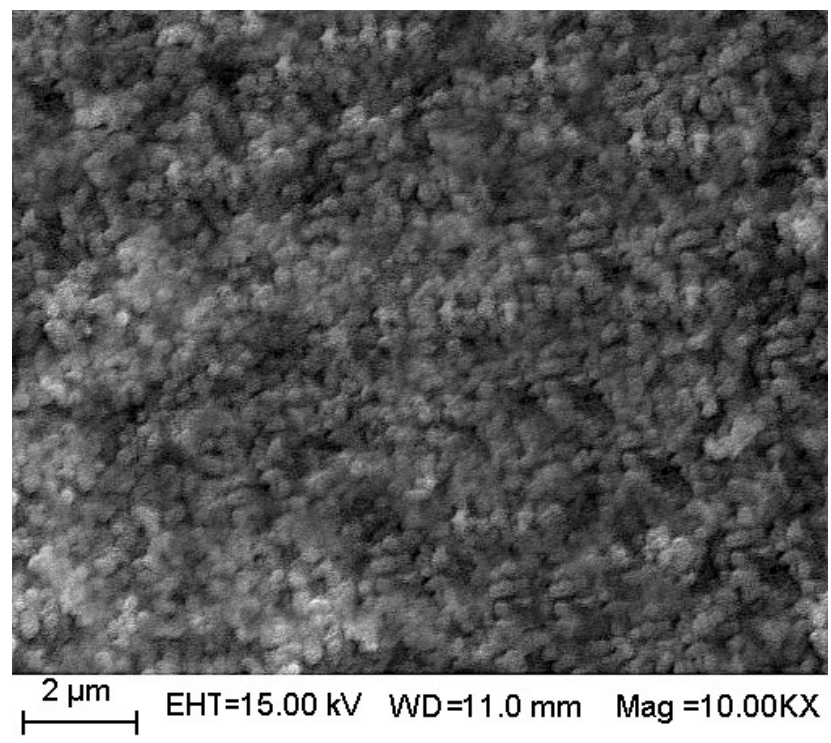

Figure 9. SEM images of $3 \mathrm{~mol} \% \mathrm{Ce}^{4+}$ doped $\mathrm{SrTiO}_{3}$.

\subsection{Optical Properties and Photocatalytic Activity}

Figure 10 was the UV-Vis diffuse reflectance spectra of pure $\mathrm{SrTiO}_{3}$ and $\mathrm{Ce}^{4+}$ doped $\mathrm{SrTiO}_{3}$ catalysts. It can be seen from Figure 10 that the absorption light region for pure $\mathrm{SrTiO}_{3}$ was only in the ultraviolet light range. However, $\mathrm{Ce}^{4+}$ doped $\mathrm{SrTiO}_{3}$ in $500 \mathrm{~nm}$ wavelength produced an observable characteristic absorption peak. The absorption peak could be ascribable to electronic transitions of $\mathrm{Ce}^{4+}$ [8]. This further proved that $\mathrm{Ce}^{4+}$ had entered into the crystal lattice of $\mathrm{SrTiO}_{3}$. In the range of $1-3 \mathrm{~mol} \%$, the absorbance intensity gradually increased. 
The absorbance of $4 \mathrm{~mol} \% \mathrm{Ce}$ doped $\mathrm{SrTiO}_{3}$ in the visible region increased significantly compared with $\mathrm{SrTiO}_{3}$. The absorbance of $4 \mathrm{~mol} \% \mathrm{Ce}$ doped $\mathrm{SrTiO}_{3}$ in the visible light range was lower than that of 1-3 mol \% doping amount. This was attributable to the change of the content of each element and the surface morphology. The results were in conformity with those of XRD BET and SEM tests.

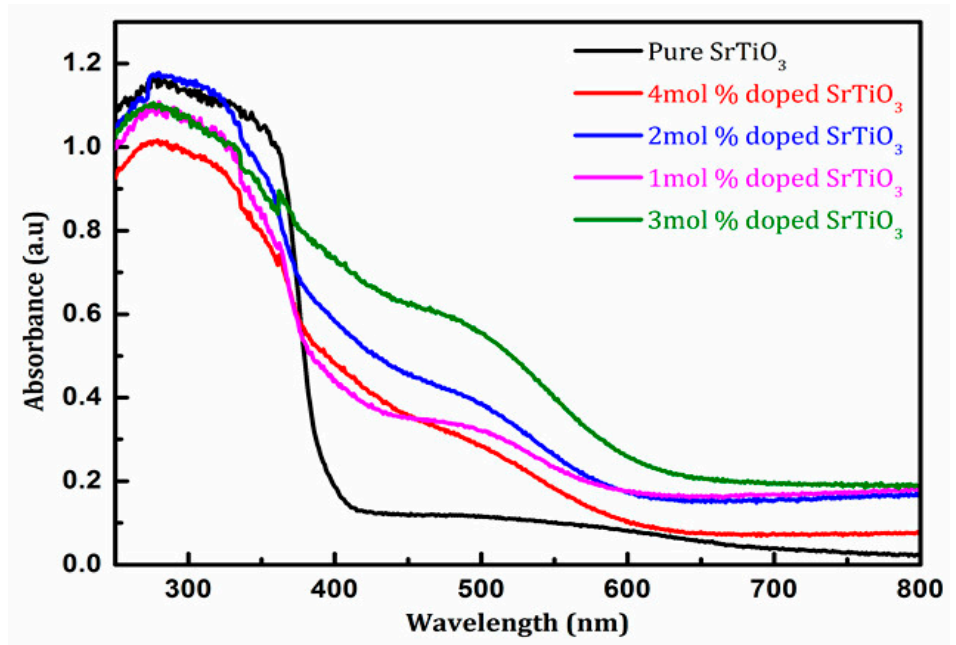

(A)

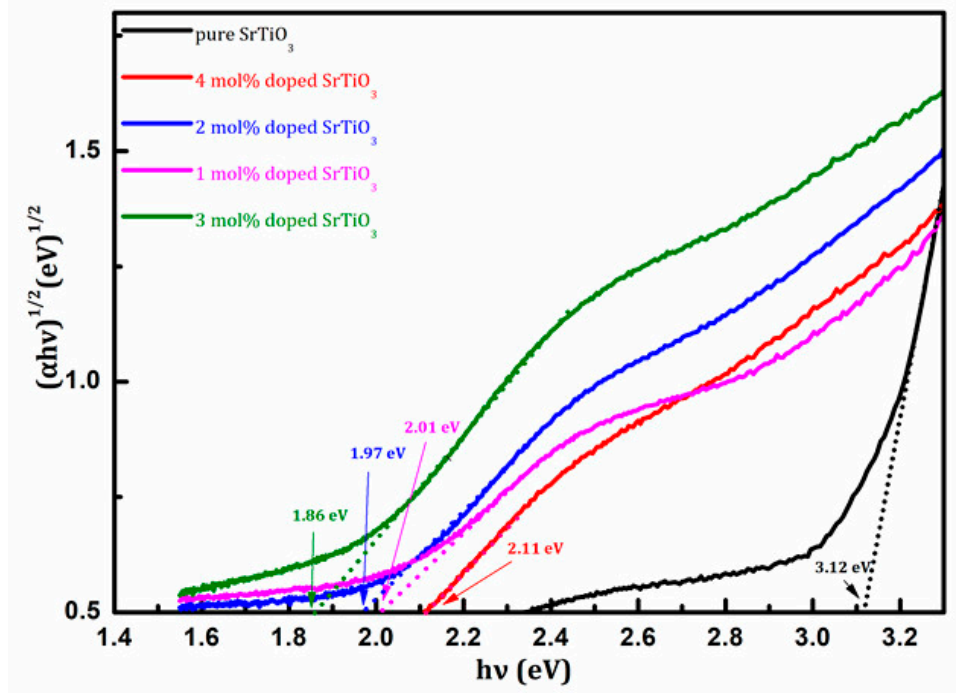

(B)

Figure 10. (A) UV-vis diffuses reflectance spectra of samples; (B) The plot of (Ahv) ${ }^{2}$ vs. hv to estimate the Eg value. (black) pure $\mathrm{SrTiO}_{3}$; (purple) $1 \mathrm{~mol} \% \mathrm{Ce}^{4+}$ doped $\mathrm{SrTiO}_{3}$; (blue) $2 \mathrm{~mol} \% \mathrm{Ce}^{4+}$ doped $\mathrm{SrTiO}_{3}$ (green) $3 \mathrm{~mol} \% \mathrm{Ce}^{4+}$ doped $\mathrm{SrTiO}_{3}$; (red) $4 \mathrm{~mol} \% \mathrm{Ce}^{4+}$ doped $\mathrm{SrTiO}_{3}$.

\subsection{Photocatalytic Activity and Corresponding Mechanism}

\subsubsection{Effect of Initial Concentration of Methylene Blue on Photocatalytic Activity}

It can be seen from Table 5 that the degradation efficiency of $100 \mathrm{mg} / \mathrm{L} \mathrm{MB}$ after $2 \mathrm{~h}$ reaction using $3 \mathrm{~mol} \% \mathrm{Ce}$ doped $\mathrm{SrTiO}_{3}$ under visible light irradiation reached $45.4 \%$ which was the highest degradation efficiency (See Figure 11). 
Table 5. Effect of initial concentration on photocatalytic activity.

\begin{tabular}{|c|c|c|c|c|c|}
\hline \multirow{2}{*}{ Samples } & \multicolumn{5}{|c|}{ Degradation Efficiency (\%) } \\
\hline & $20 \mathrm{mg} / \mathrm{L}$ & $50 \mathrm{mg} / \mathrm{L}$ & $100 \mathrm{mg} / \mathrm{L}$ & $150 \mathrm{mg} / \mathrm{L}$ & $200 \mathrm{mg} / \mathrm{L}$ \\
\hline $\mathrm{SrTiO}_{3}$ & 3.8 & 4.7 & 6.1 & 5.6 & 4.5 \\
\hline $1 \mathrm{~mol} \% \mathrm{Ce}^{4+}$ doped $\mathrm{SrTiO}_{3}$ & 10.1 & 15.5 & 18.6 & 17.2 & 15.6 \\
\hline $2 \mathrm{~mol} \% \mathrm{Ce}^{4+}$ doped $\mathrm{SrTiO}_{3}$ & 12.7 & 21.8 & 31.4 & 29.6 & 23.1 \\
\hline $3 \mathrm{~mol} \% \mathrm{Ce}^{4+}$ doped $\mathrm{SrTiO}_{3}$ & 27.2 & 36.2 & 45.4 & 39.4 & 35.4 \\
\hline $4 \mathrm{~mol} \% \mathrm{Ce}^{4+}$ doped $\mathrm{SrTiO}_{3}$ & 4.3 & 8.7 & 12.4 & 9.7 & 7.6 \\
\hline
\end{tabular}

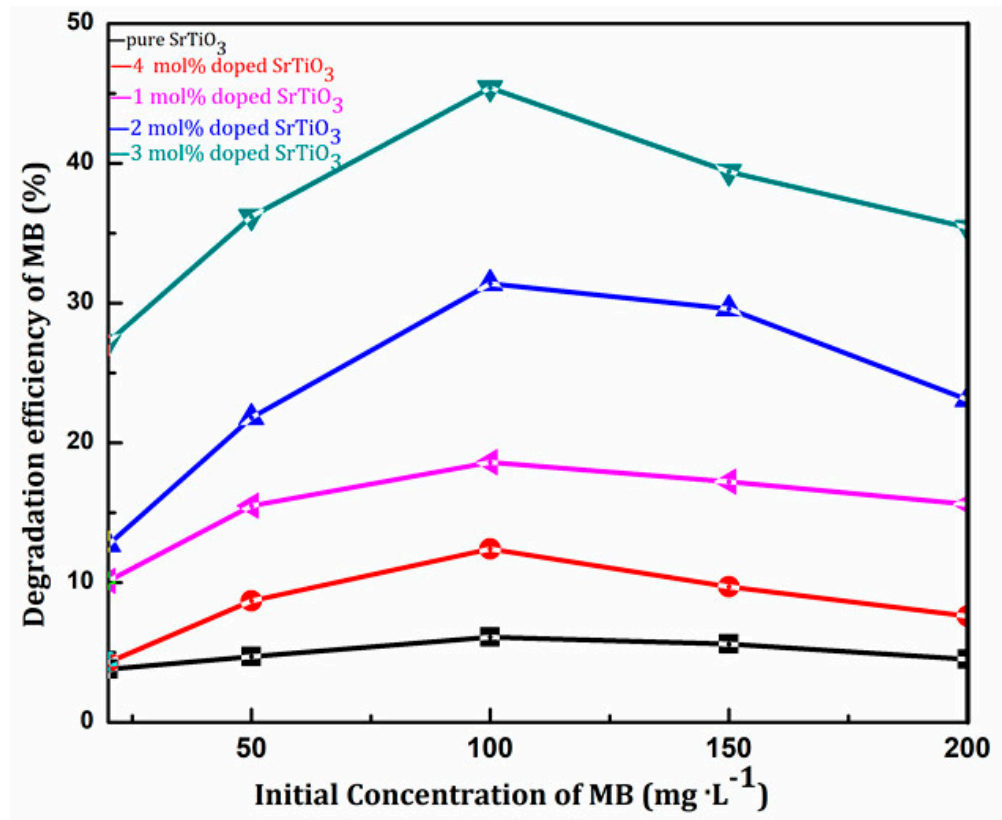

Figure 11. Effect of initial concentration on photocatalytic activity. (black) pure $\mathrm{SrTiO}_{3}$; (purple) $1 \mathrm{~mol} \% \mathrm{Ce}^{4+}$ doped $\mathrm{SrTiO}_{3}$; (blue) $2 \mathrm{~mol} \% \mathrm{Ce}^{4+}$ doped $\mathrm{SrTiO}_{3}$; (green) $3 \mathrm{~mol} \% \mathrm{Ce}^{4+}$ doped $\mathrm{SrTiO}_{3} ;$ (red) $4 \mathrm{~mol} \% \mathrm{Ce}^{4+}$ doped $\mathrm{SrTiO}_{3}$.

The lower the initial concentration of methylene blue, the lighter the color was. Thus, the light source had a strong penetrating ability in the solution. However, a lower initial concentration resulted in making concentration diffusion the rate-controlling step in the whole photocatalytic kinetics. In such an occurrence, photocatalytic effect decreased.

However, when the MB concentration was greater than $100 \mathrm{mg} / \mathrm{L}$, the solution color was darker, which significantly obstructed the absorption to visible light and further affected the optimal degradation action. Therefore, the concentration of methylene blue $(100 \mathrm{mg} / \mathrm{L})$ was chosen to investigate the photocatalytic activity for the subsequent test.

\subsubsection{Photocatalytic Activity and Mechanism}

From Figure 12, we can observe the maximum degradation efficiency of methylene blue for pure $\mathrm{SrTiO}_{3}$ was only $40 \%$. The photocatalytic activity gradually increased with the increase in doped $\mathrm{Ce}^{4+}$ content. The degradation efficiency of methylene blue could reach to $98.7 \%$ using $3 \mathrm{~mol} \% \mathrm{Ce}^{4+}$ doped $\mathrm{SrTiO}_{3}$.

(1) According to the photocatalytic mechanism of $\mathrm{SrTiO}_{3}$ (Figure 12), under light irradiation, the photogenerated electron and hole separated and moved to different locations on the particle surface to participate redox reactions for organic compounds degradation. The recombination of the photogenerated electron and hole was one of the reasons for the low photocatalytic efficiency of 
$\mathrm{SrTiO}_{3} . \mathrm{XRD}, \mathrm{BET}$ and SEM tests indicated that as the average particle size of $\mathrm{Ce}^{4+}$ doped $\mathrm{SrTiO}_{3}$ decreased, the specific surface area increased. The photo-excited electron and hole needed to migrate to the surface to play the catalytic role. The smaller the particle size, the shorter migration distance was [18]. Accordingly, the recombination possibility of the photo-excited electron and hole became smaller. In addition, the $\mathrm{Ce}^{4+}$ doping improved agglomeration. The surface of the catalyst active center was able to absorb ultraviolet light irradiation [19] which enhanced photocatalytic performance.

(2) Figure 13 shows that the adsorption oxygen on the surface of $\mathrm{SrTiO}_{3}$ quickly captured electrons to inhibit recombination of photo-excited electron and hole. Meanwhile, it also could adsorb oxygen and $\mathrm{H}_{2} \mathrm{O}$ to produce $\cdot \mathrm{OH}$ and $\mathrm{h}^{+}$. The photo-excited hole could directly transform the surface adsorption of $\mathrm{H}_{2} \mathrm{O}$ into $\cdot \mathrm{OH}$, which was the active center [20,21]. From the analysis of XPS, $\mathrm{Ce}^{4+}$ doping increased the amount of surface adsorption of oxygen and $\mathrm{H}_{2} \mathrm{O}$. Thus, $\mathrm{Ce}^{4+}$ doped $\mathrm{SrTiO}_{3}$ could produce more $\cdot \mathrm{OH}$ to enhance photocatalytic ability.

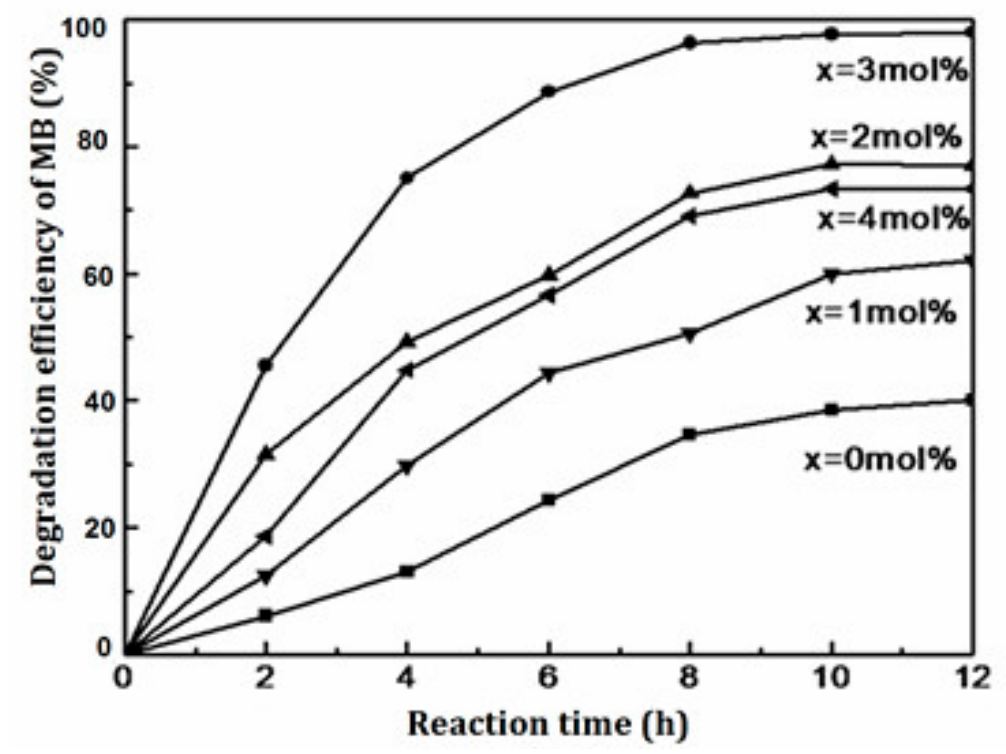

Figure 12. The photocatalytic degradation on $\mathrm{MB}$ of $0 \sim 4 \mathrm{~mol} \% \mathrm{Ce}^{4+}$ doped $\mathrm{SrTiO}_{3}$.

(3) In addition, the UV-vis diffuse reflectance spectrum demonstrated that the band gap width of $3 \mathrm{~mol} \% \mathrm{Ce}^{4+}$ doped $\mathrm{SrTiO}_{3}$ became smaller (See Figure 10). This was because the $\mathrm{Ce}^{4+}$ doping could introduce the $4 \mathrm{f}$ orbital energy level into the midst band gap of $\mathrm{SrTiO}_{3}$. On the one side, this reduced the band gap of $\mathrm{SrTiO}_{3}$, which made the excitation wavelength of $\mathrm{SrTiO}_{3}$ shift from the ultraviolet light range to the visible light range, boosting the utilization rate of visible light. On the other side, this created new energy states, namely, mid gap states, that facilitated the photo-excited electron to jump into the conduction band and to achieve effective separation between the photo-excited electron and the hole. In other words, the doping of $\mathrm{Ce}^{4+}$ could create new energy states that could delay the exciton recombination time and could allow charge separation. 


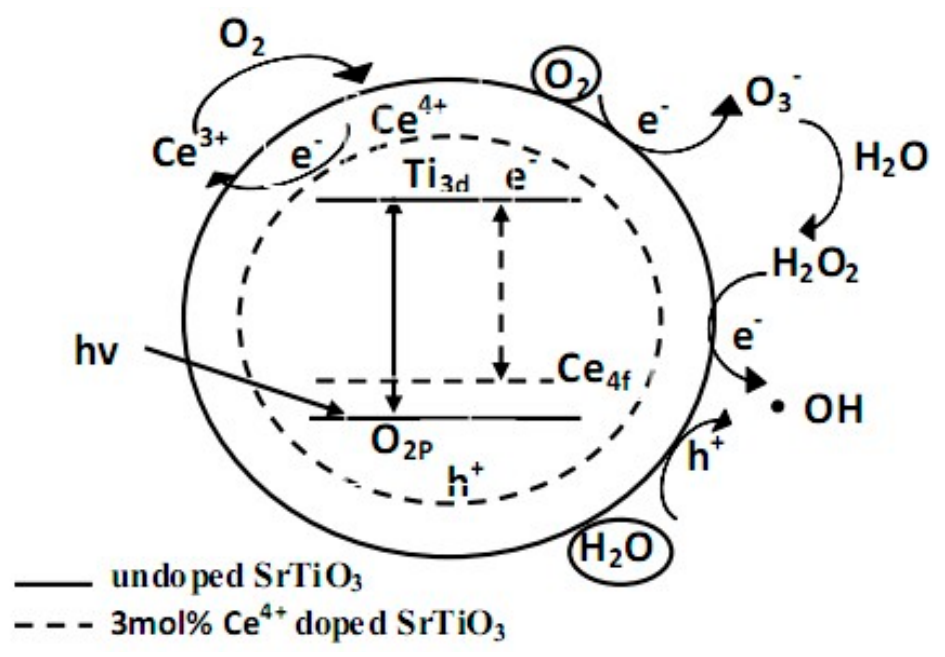

Figure 13. Schematic diagram of photocatalytic mechanism.

(4) Furthermore, the reduction potential of $\mathrm{Ce}^{4+} / \mathrm{Ce}^{3+}$ was $1.61 \mathrm{eV}$. Ce $\mathrm{e}^{4+}$ on $4 \mathrm{f}$ energy level easily captured electrons to generate $\mathrm{Ce}^{3+}$. The generated $\mathrm{Ce}^{3+}$ in turn could be oxidized to $\mathrm{Ce}^{4+}$ by oxygen on the catalyst surface or in the air [22]. The photoexcited electron was captured continuously by $\mathrm{Ce}^{4+}$, which further inhibited the recombination between the photo-excited electron and the hole.

In comparison to $3 \mathrm{~mol} \% \mathrm{Ce}^{4+}$ doped $\mathrm{SrTiO}_{3}$, photocatalytic activity of $4 \mathrm{~mol} \% \mathrm{Ce}^{4+}$ doped $\mathrm{SrTiO}_{3}$ decreased. An excessively doped $\mathrm{Ce}^{4+}$ increased the size of the catalyst particle size. Moreover, $\mathrm{n}(\mathrm{Sr}) / \mathrm{n}(\mathrm{Ti})$ in the $\mathrm{Ce}^{4+}$ doped $\mathrm{SrTiO}_{3}$ increased (See Table 4), indicating that excessive doping brought out the generation of $\mathrm{SrO}$ on the surface of $\mathrm{SrTiO}_{3}$, which impeded the light absorption for $\mathrm{SrTiO}_{3}$ and affected its catalytic activity.

\section{Conclusions}

(1) The tartaric acid aqueous solution is used as a solvent, dispersant, and stabilizer to prepare $\mathrm{SrTiO}_{3}$ using the sol-gel method. The improved preparation method has some advantages, for example, the simplicity of the process with less equipment, its short preparation time, and its low cost. When $1.47 \mathrm{~g} \mathrm{SrCO}_{3}$ was weighted to synthesize $\mathrm{SrTiO}_{3}$, the optimum molar ratio of $\mathrm{Sr}^{2+}$ and tartaric acid was 1:4. The optimum amount of distilled water was $20 \mathrm{~mL}$. In practical application, we can adjust the molar ratio $\left(\mathrm{Sr}^{2+}\right.$ - tartaric acid) and the amount of water on the basis of the quality of $\mathrm{SrCO}_{3}$.

(2) The degradation efficiency of methylene blue reached $98.7 \%$ using $3 \mathrm{~mol} \% \mathrm{Ce}^{4+}$ doped $\mathrm{SrTiO}_{3}$, indicating it had an excellent photocatalytic activity. The introduction of $\mathrm{Ce}^{4+}$ into the $\mathrm{SrTiO}_{3}$ revealed several prominent advantages: (i) The $\mathrm{Ce}^{4+}$ doping increased specific surface area more than four times compared with pure $\mathrm{SrTiO}_{3}$; (ii) The doped $\mathrm{Ce}^{4+}$ enhanced the physical adsorption of $\mathrm{H}_{2} \mathrm{O}$ and adsorbed oxygen on the surface of $\mathrm{SrTiO}_{3}$ to produce more catalytic active centers; (iii) The incorporation of $\mathrm{Ce}^{4+}$ into the crystal lattice for $\mathrm{SrTiO}_{3}$ created mdi gap states that delay the exciton recombination time and allow for charge separation; (iv) $\mathrm{Ce}^{4+}$ repeatedly captured photoelectron to produce $\mathrm{Ce}^{3+}$, which inhibited the recombination of photogenerated electrons and holes.

Acknowledgments: We want to thank the financial support from Youth research talents' growth support program of Yangtze Normal University and Chongqing Basic Science and Advanced Technology Research Program (CSTC2015jcyjBX0015). We gratefully acknowledge many important contributions from the researchers of all reports cited in our paper.

Author Contributions: Taiping Xie and Longjun Xu conceived and designed the experiments; Yuan Wang performed the experiments; Yuan wang and Taiping Xie analyzed the data; Chenglun Liu contributed reagents/materials/analysis tools; Taiping Xie and Yuan wang wrote the paper.

Conflicts of Interest: The authors declare that they have no conflict of interest. 


\section{References}

1. Cao, T.P.; Li, Y.J.; Wang, C.H.; Shao, C.L.; Liu, Y.C. A Facile in Situ Hydrothermal Method to $\mathrm{SrTiO}_{3} / \mathrm{TiO}_{2}$ Nanofiber Heterostructures with High Photocatalytic Activity. Langmuir 2011, 27, 2946-2952. [CrossRef] [PubMed]

2. Mao, M.Y.; Li, Y.Z.; Hou, J.T.; Zeng, M.; Zhao, X.J. Extremely efficient full solar spectrum light driven thermocatalyticactivity for the oxidation of VOCs on OMS-2 nanorod catalyst. Appl. Catal. B 2015, 174, 496-503. [CrossRef]

3. Xie, T.P.; Xu, L.J.; Liu, C.L. Magnetic composite BiOCl-SrFe ${ }_{12} \mathrm{O}_{19}$ : A novel p-n type heterojunction with its enhanced photocatalytic activity. Dalton Trans. 2014, 43, 2211-2220. [CrossRef] [PubMed]

4. Navarro, R.M.; Alvarez-Galvan, M.C.; de la Mano, J.A.V. A framework for visible-light water splitting. Energy Environ. Sci. 2010, 3, 1865-1882. [CrossRef]

5. Wang, L.; Ji, Z.Y.; Lin, J.J.; Li, P. Preparation and optical and photocatalytic properties of Ce-doped ZnO microstructures by simple solution method. Mater. Sci. Semicon. Proc. 2017, 71, 401-408. [CrossRef]

6. Rezaei, M.; Habibi-Yangjeh, A. Simple and large scale refluxing method for preparation of Ce-doped ZnO nanostructures as highly efficient photocatalyst. Appl. Surf. Sci. 2013, 265, 591-596. [CrossRef]

7. Adel, M.F.; Ahmed, A.I.; Ibrahim, A.; Bouzid, H.; Al-Sayari, S.A. Highly efficient photocatalyst based on Ce doped $\mathrm{ZnO}$ nanorods: Controllable synthesis and enhanced photocatalytic activity. Chem. Eng. J. 2013, 229, 225-233.

8. Piña-Pérez, Y.; Tzompantzi-Morales, F.; Pérez-Hernández, R.; Arroyo-Murillo, R.; Acevedo-Peña, P.; Gómez-Romero, R. Photocatalytic activity of $\mathrm{Al}_{2} \mathrm{O}_{3}$ improved by the addition of $\mathrm{Ce}^{3+} / \mathrm{Ce}^{4+}$ synthesized by the sol-gel method. Photodegradation of phenolic compounds using UV light. Fuel 2017, 198, 11-21. [CrossRef]

9. Bharatvaj, J.; Preethi, V.; Kanmani, S. Hydrogen production from sulphide wastewater using $\mathrm{Ce}^{3+} \mathrm{TiO}_{2}$ photocatalysis. Int. J. Hydrogen Energy 2018, 43, 3935-3945. [CrossRef]

10. Ong, C.B.; Ng, L.Y.; Mohammad, A.W. A review of ZnO nanoparticles as solar photocatalysts: Synthesis, mechanisms and applications. Renew. Sust. Energy Rev. 2018, 81, 536-551. [CrossRef]

11. Hou, D.F.; Hu, X.L.; Ho, W.K.; Hu, P.; Huang, Y.H. Facile fabrication of porous Cr-doped $\mathrm{SrTiO}_{3}$ nanotubes by electrospinning and their enhanced visible-light-driven photocatalytic properties. J. Mater. Chem. A 2015, 3, 3935-3943. [CrossRef]

12. Lehuta, K.A.; Kittilstved, K.R. Speciation of $\mathrm{Cr}$ (III) in intermediate phases during the sol-gel processing of Cr-doped $\mathrm{SrTiO}_{3}$ powders. J. Mater. Chem. A 2014, 2, 6138-6145. [CrossRef]

13. Canu, G.; Buscaglia, V. Hydrothermal synthesis of strontium titanate: Thermodynamic considerations, morphology control and crystallisation mechanisms. Cryst. Eng. Comm. 2017, 19, 3867-3891. [CrossRef]

14. Ha, M.N.; Zhu, F.; Liu, Z.; Wang, L.; Liu, L.; LU, G.; Zhao, Z. Morphology-Controlled Synthesis $\mathrm{SrTiO}_{3} / \mathrm{TiO}_{2}$ Heterostructures and Their Photocatalytic Performance for Water Splitting. RSC Adv. 2016, 6, 21111-21118. [CrossRef]

15. Xie, T.P.; Liu, C.L.; Xu, L.J. Novel heterojunction $\mathrm{Bi}_{2} \mathrm{O}_{3} / \mathrm{SrFe}_{12} \mathrm{O}_{19}$ magnetic photocatalyst with highly enhanced photocatalytic activity. J. Phys. Chem. C 2013, 117, 24601-24610. [CrossRef]

16. Liu, F.M.; Xie, Y.; Yu, C.L.; Liu, X.M.; Dai, Y.H.; Liu, L.J. Novel hybrid Sr-doped $\mathrm{TiO}_{2} / \mathrm{magnetic}$ $\mathrm{Ni}_{0.6} \mathrm{Zn}_{0.4} \mathrm{Fe}_{2} \mathrm{O}_{4}$ for enhanced separation and photodegradation of organics under visible light. RSC Adv. 2015, 5, 24056-24063. [CrossRef]

17. Kutty, T.R.N.; Nag, A. Role of interface states associated with transitional nanophase precipitates in the photoluminescence enhancement of $\mathrm{SrTiO}_{3}: \mathrm{Pr}^{3+}, \mathrm{Al}^{3+}$. J. Mater. Chem. 2003, 13, 2271-2278. [CrossRef]

18. Saadetnejad, D.; Yildirim, R. Photocatalytic hydrogen production by water splitting over Au/ $\mathrm{Al}-\mathrm{SrTiO}$. Int. J. Hydrogen Energy 2018, 43, 1116-1122. [CrossRef]

19. Shah, Z.H.; Ge, Y.Z.; Ye, W.Y. Visible light activation of $\mathrm{SrTiO}_{3}$ by loading $\mathrm{Ag} / \mathrm{AgX}(\mathrm{X}=\mathrm{Cl}, \mathrm{Br})$ for highly efficient plasmon-enhanced photocatalysis. Mater. Chem. Phys. 2017, 198, 73-82. [CrossRef]

20. Wang, C.D.; Qiu, H.; Inoue, T.; Yao, Q.W. Band gap engineering of $\mathrm{SrTiO}_{3}$ for water splitting under visible light irradiation. Int. J. Hydrogen Energy 2014, 39, 12507-12514. [CrossRef] 
21. Sakata, Y.; Miyoshi, Y.; Maeda, T.; Ishikiriyama, K. Photocatalytic property of metal ion added $\mathrm{SrTiO}_{3}$ to Overall $\mathrm{H}_{2} \mathrm{O}$ splitting. Appl. Catal. A 2016, 521, 227-232. [CrossRef]

22. Dong, B.; Lia, L.Y.; Dong, Z.F.; Xu, R.; Wu, Y. Fabrication of $\mathrm{CeO}_{2}$ nanorods for enhanced solar photocatalysts. Int. J. Hydrogen Energy 2018, 43, 5275-5282. [CrossRef] 